\title{
A PRACTICE OF MIXED TEACHING MODES IN UNIVERSITY PHYSICS COURSE BASED ON AN APPLICATION CALLED RAIN CLASSROOM
}

\author{
Qingping Dou, Mingliang Zhang \\ School of Intelligent Systems Science and Engineering, Jinan University (Zhuhai \\ Campus), Zhuhai 519070, China. \\ Email: tdouqingping@jnu.edu.cn
}

\begin{abstract}
Based on the related analysis of mixed teaching, this article takes teaching practice in Jinan University as an example to make a preliminary analysis of the application of Rain Classroom in the teaching process. During the teaching process, a mixed teaching activity with the Rain Classroom was designed. Related questionnaire surveys, test score analysis, and Rain Classroom data analysis were conducted from the students who had taken the University Physics course.
\end{abstract}

KEYWORDS: mobile learning, university physics, mixed teaching

\section{INTRODUCTION}

With the development of Internet technology, new challenges has been brought into education. Actively using information technology represented by "Internet + Education" to achieve a student-centered mixed teaching modes is one of the hot spots currently being explored (Bian Weiwei, 2019). Jinan University introduced the Rain Classroom intelligent platform which can organically integrate tools into daily teaching, optimize teaching resources, teaching process, and analysis of teaching cycle data and teaching evaluation. It quantifies the learning situation to help teachers accurately teach and achieve intelligence-based blended smart teaching for teaching applications. During the class, the teaching courseware is pushed to the students' mobile terminal. Teachers and students interact in multiple and real-time manners. Students can answer questions, vote, and pop-up interactions in real time, effectively mobilize students' classroom enthusiasm and improve learning efficiency of student. MOOC videos, exercises, and voice previews or review courseware are pushed to the students' mobile terminal (Li Xiangming, 2017). Teachers and students communicate in a timely manner to achieve classroom flipping.

In 1946, Edgar Dale of the United States proposed the Cone of Learning theory (Lee, S. J., 2007). The first learning method is listening. The teacher is lecturing while students are listening to the teacher. This is the most familiar and most commonly used method. The learning effect is the lowest, leaving only $5 \%$ of the content learned after two weeks. Second, what you learn through reading can be retained by $10 \%$. The third way is to learn by sound, picture, which can reach $20 \%$ of the teaching content. The fourth is demonstration. With this method of learning, students can remember $30 \%$. The fifth, group discussion, can remember $50 \%$ of the content. The sixth type, learning by doing or actual drill, can reach $75 \%$. From the theory Cone of Learning, we can see that the traditional teaching method of students listening has the lowest learning efficiency, 
while the group discussion and learning by doing methods have the highest learning effect.

\section{THEORY AND APPLICATION}

The University Physics course is a subject-based course for all first-year students of science and engineering majors. It is a compulsory course with a strong theoretical basis. Every science and engineering student has studied physics since junior high school. They have studied physics for six years when they come into a university, and have a certain foundation of physics. University physics is an extension of physics in middle school. University physics is explained and expressed with advanced mathematics knowledge, but the application of university physics is very far-reaching, and middle school physics is inadequate. When many students get university physics textbooks, the first feeling is "I have learned, how simple the content is". So it leads to inattention at the beginning of study. Learn to learn, the second feeling is "it is so hard to learn, the law theorem I know, why could not I analyze various problems". This led to some students abandoning their studies and even postponing graduation because of failure in the final test of this compulsory course.

The current era is the information age. The mobile phone is a mobile office, and the amount of information is so large that we all can't handle it. For young university students, their self-control and ability to recognize and receive information have not reached the level where they can choose to receive it, so digital information might cause them to be lost in a state of wasting time. In the traditional classroom teaching process, the teacher speaks with cadence rising and falling on the podium, but the voice could not get into the students' ears, because the students are looking at the sreen of mobile phones, or they are wandering to read the information on the mobile phone. Students' mind is definitely not in the classroom. No matter how abundant the teaching content, some students are always in this state. Most of the information browsed by students is spam. To this end, teaching reform is imperative (Wei Sun, 2019).

Rain Classroom is an application program developed for mobile learning which integrates the information preparation before class, the real-time interaction in class (Liu Weiwei, 2019). Using the Rain Classroom for mixed teaching, students use the mobile phone that does not leave their hands at all times to learn, watch PPT, and learn the content of online course, so that students can look at mobile phones with purpose and task, helping students to change their blindness of browsing information. In the teaching classroom, students are not just audiences. They must participate in the teaching process, actively participate in discussions, find problems and solve problems, and actively display their learning results.

\section{A MIXED TEACHING MODE}

\section{General idea of mixed teaching based on Rain Classroom}

Effective teaching is a dance between teachers and students. The creative and colorful teaching classrooms allow students to gain a broad and profound cultural influence. In terms of the learning environment, the class teacher creates a virtual class through Rain 
Classroom, and shares pre-course review and post-course review materials with MOOC videos, exercises, and speech in order to grasp the student's preview and review situation in real time (Shuaiguo Wang, 2018). Students at any time study the materials pushed in the Rain Classroom anywhere, and feedback the problems encountered in real time to the teacher. The whole teaching process is full of intellectual challenges, enabling students to learn and master knowledge through various problem-solving processes.

The construction of the smart classroom of University Physics course is mainly carried out from the following aspects:

(1) The classroom is dynamic and open to enhance teacher-student interaction. The construction of smart classroom is the construction of classroom teaching aimed at knowledge. Teacher teaching and student learning are the main content of smart classrooms, and interaction between teachers and students is an important focus of smart classrooms.

(2) Students' individual learning and optimization of knowledge transmission. Smart classroom is based on learning and teaching, and people-oriented. When problems occur, they are solved in real time. The so-called knowledge, on the first level, refers to the specific content of subject teaching. For university physics, it means physics theorems, laws, and applications in daily life. The second level is specific methods and techniques when learning specific content. Smart classroom can achieve the best combination of individual learning and optimized knowledge transmission.

(3) Smart application in the classroom, perfect combination of teaching and learning. Smart classroom is an innovative teaching mode, which is reflected in learning activities and teaching process. Intelligent management, efficient student-teacher interaction. In the instruction of this course, the students' understanding of the knowledge they have learned and the degree of cognition are used as the evaluation standards of classroom teaching effects to maximize the capacity of classroom teaching knowledge.

Before Class

- Pre-class Study Guide

- Student Self-study

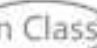

- Rain Classroom

- Real Time Interaction

- Review and Test

- Well-timed Adjustment

\section{Figure 1. Overall Teaching Procedure based on Rain Classroom}

Overall teaching procedure based on Rain Classroom is shown in Figure 1.

(1) Preparation of Class: Using the Rain Classroom, we construct the teaching model for University Physics and the materials preparation before class as shown is Figure 2. 
Vol.8, Issue 3, pp.194-200, March 2020

Published by ECRTD- UK

Print ISSN: ISSN 2054-6351

Online ISSN: ISSN 2054-636X

(2) Classroom teaching: The flow diagram of classroom teaching is shown in Figure 3. The smart class is organized by the teacher, but it serves for the students. There are the online test and the contribute function in the class for understanding the leaning situations for the students. In the whole teaching process, the students actively participate. According to the Cone of Learning theory, the discussion, and learn by doing, and doing by learning, will greatly improve the efficiency for the students.

(3) After class analysis: We will analyze the data from the Rain Classroom, around the dates before class and after class. We will get the situations of the students in reality. According to that real situation, we will understand how are the students doing. In next class, we will highlight these points that students do not understand correctly.

The basic requirements for the knowledge points

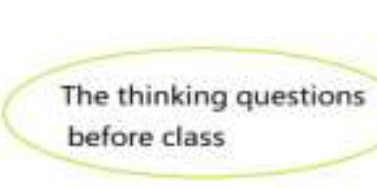

Selected the

knowledge points

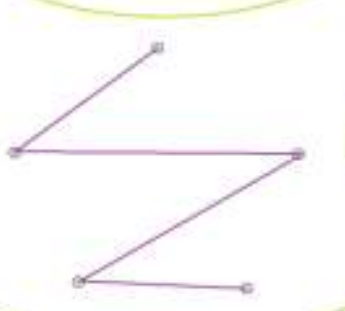

Answer the thinking

questions for the studens
The learning video

before the class

Figure 2. Material preparation before class

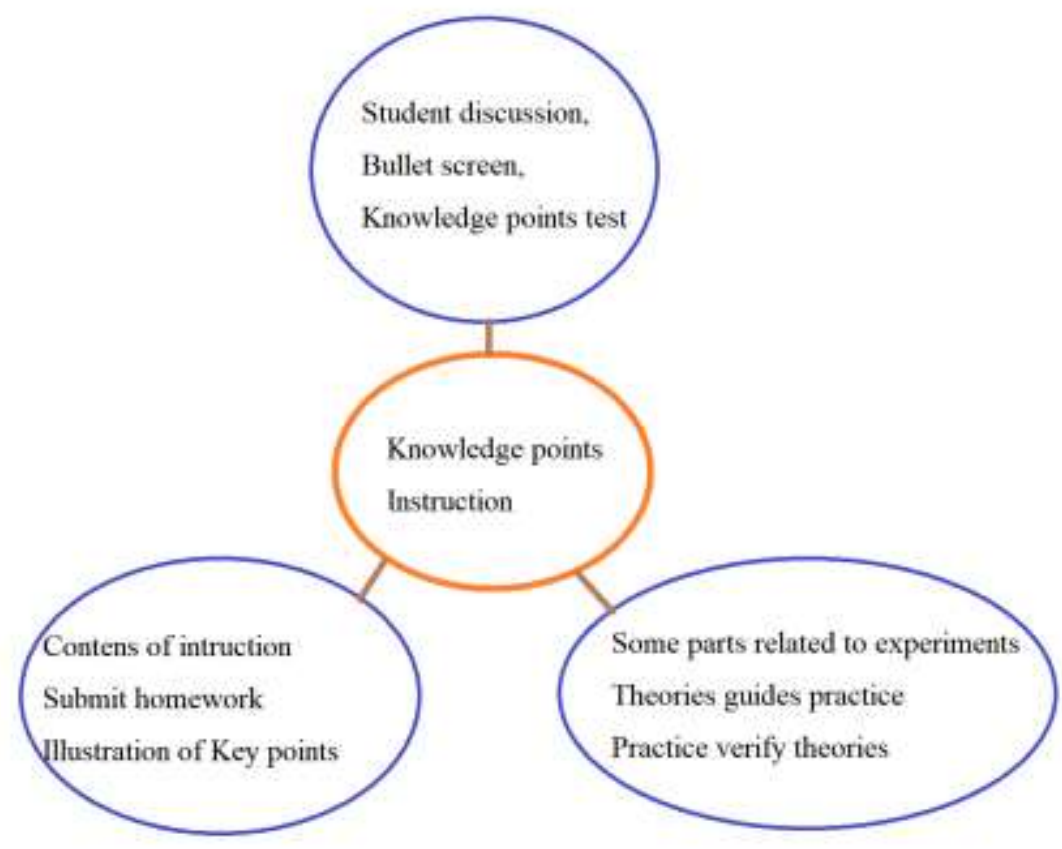

Figure 3. Structure of the instruction in class 


\section{The Actual Operation of Mixed Teaching Model}

(1) Interaction in real time, feedback about difficulties from the students

With the software Rain Classroom, the teacher turns on the teaching on the desktop of a computer. At the same time, the students' mobile phones terminal receive a real-time push message prompt and reads the full text to start the class. When browsing the courseware, students can use the "collection" and "don't understand" buttons on each page of the courseware to mark the knowledge points that they don't understand in the course. Teachers will receive anonymous "don't understand" data feedback to adjust the course rhythm and focus on explaining.

(2) Problems discussion

Teachers can post relevant topic through the rain class; Students submit online or paperbased materials. Teachers can grasp the students' understanding level of the problems based on the answers submitted by the students.

(3) Release the test paper

Teachers can help students deepen their understanding of knowledge by publishing project test functions (currently multiple-choice questions). Teachers can learn the basics of students' knowledge of the classroom and the completion of educational goals in time, helping teachers to properly arrange teaching progress and content, and to adapt to the whole class students in a reasonable manner. With the help of Rain Classroom, students' acceptance of new knowledge can be examined, and the teaching focus can be adjusted quickly and promptly.

\section{RESULTS AND DISCUSSION}

In the spring semester of 2019, the university physics course apply the Rain Classroom into the teaching method. There are three classes with 485 students. The bar chart about the final test is shown in Figure 4. The average scores which is 64 points of the three classes are almost the same, and the number of people in each class of each class is basically the same. The average test score in previous years may be as much as 5 points lower, and there were more students who dropped out of a class. This situation was improved through the rain class teaching, and the students' enthusiasm for learning in each class was greatly improved.

From the teaching and students' examination situation, students can actively participate in teaching process, online preview, interaction with teachers, and other activities can actively participate in, and can complete relevant assignments and discussions; but in the final examination we find students do not have a firm grasp of the basic common sense of physics. Many students do not add units after calculating physical quantities. On one hand, it indicates that students are not studying hard enough, on the other hand, some students do not have a thorough understanding of the application of basic principles. They are not careful enough to give physical quantities and even cannot distinguish between vectors and scalars. But on the whole, students' learning attitude is more positive than ever through the teaching method with Rain Classroom. 


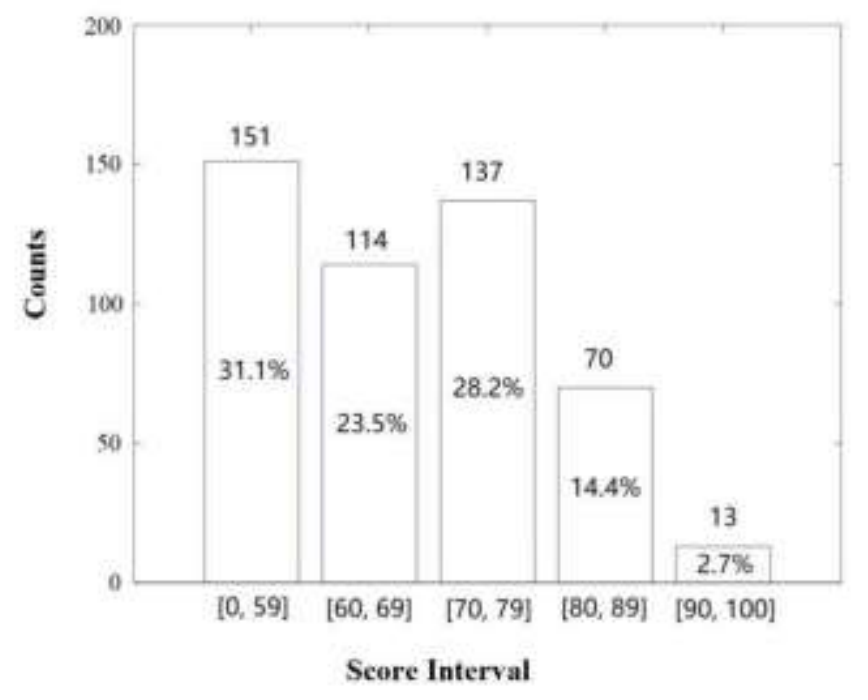

Figure 4. Bar chart for the scores of the final test

A questionnaire survey was conducted at the end of the semester. From the results of the students' choice of questionnaires:

(1) Teaching method: Accounting for $76 \%$ of the respondents prefer the combination of online and offline teaching. The traditional teaching method is more suitable for certain teaching content. For other teaching content, the use of rain classroom will be more effective.

(2) The help of Rain Classroom for learning: Most students chose to increase communication between teachers and students and Rain Classroom provided a bridge that enable effective communication.

(3) Insufficiency of Rain Classroom: Some students chose that the teacher could not really understand the learning situation of the students. Because the teacher can't really supervise the pre-class review and post-class review. The students had certain fraudulent tendency; Some students chose to have too high requirements for the network, which is indeed an unavoidable problem. In the normal course teaching, there are often network interruptions and delays in class. In many cases, they can only choose to give up using Rain Classroom.

(4) Important functions for Rain Classroom: Some students chose to diversify the class. The use of Rain Class enriches the teaching methods and makes the boring theoretical class more colorful.

\section{CONCLUSION}

We constructed the smart classroom of University Physics through the study of University Physics course, students can build a map of physics knowledge, so that the learned knowledge can be digested. This article combines the theory of Cone Learning, and integrates discussion, learning by doing, and doing by learning, to maximize the learning efficiency of students. In the teaching process, the application of Rain Classroom has strengthened the interaction between teachers and students, enabling 
Vol.8, Issue 3, pp.194-200, March 2020

Published by ECRTD- UK

Print ISSN: ISSN 2054-6351

Online ISSN: ISSN 2054-636X

teachers to understand the students' learning dynamics and the mastery of the learning content at the first time, so as to promote teaching and learning.

The organizer of a smart classroom is a teacher, but the organization and construction of a smart classroom is for the students. Make full use of the quick classroom quiz function of Rain Classroom to understand the students' understanding in real time. During the entire teaching process, students actively participate in it, which will greatly improve the learning efficiency of students. Utilizing the powerful data functions of Rain Classroom, analyze the data before, during, and after the class, to get the actual learning situation of students, and to understand the poor understanding of students. In the next class, special emphasis will be given to explanations. Using the data provided by Rain Classroom, students' learning situation can be seen at a glance, and the knowledge dissemination process can be optimized more reasonably.

\section{References}

Bian Weiwei, Xiao Ji, Xiaoqiang Qin, Yujia Kong, Chunzhen Zhao, (2019) Practical Exploration of the "Rain Classroom-Flipped Classroom" Mode in Basic Chemistry Course, Proceedings of the 2nd International Seminar on Education Research and Social Science (ISERSS 2019)

Lee, S. J., Reeves, T. C. (2007). Edgar Dale: A significant contributor to the field of educational technology. Educational Technology, 47(6), 56.

Liu Weiwei, Weiwei Liu, (2019) Research on the Teaching Mode of Higher Vocational English Flipped Classroom Based on Rain Classroom Application, Proceedings of the 2019 5th International Conference on Social Science and Higher Education (ICSSHE 2019)

Li Xiangming, Shuqiang Song, (2017) Mobile technology affordance and its social implications: A case of "Rain Classroom", British Journal of Educational Technology

Shuaiguo Wang,Youjie Chen, (2018) Rain classroom: a tool for blended learning with MOOCs, Proceedings of the Fifth Annual ACM Conference on Learning at Scale, Article No.: 27 Pages 1-2

Wei Sun, (2019) Flipped Classroom Teaching of College English Based on "Rain Classroom", In Advances in Intelligent Systems and Computing 1088, Data Processing Techniques and Applications for Cyber-Physical Systems (DPTA 2019), (C. Huang et al. eds.) 